\title{
A Construção Simbólica na Gestão da Marca Havaianas
}

- Gabriela Botelho Mager

- Alberto Cipiniuk2 


\title{
A Construção Simbólica na Gestão da Marca Havaianas
}

\begin{abstract}
RESUMO
Considera-se a contemporaneidade como a era das marcas, a qual é onipresente e onipotente. O objetivo nesta pesquisa foi o de estudar o lugar social da marca na contemporaneidade, configurado nas esferas sociais e culturais, a fim de identificar a ocorrência do processo de valorização de sua imagem. O capital simbólico eleva o capital econômico e cria uma relação de identidade com seus clientes. O massivo investimento em comunicação nos diversos meios faz com que haja inculcação da marca nas mentes e a inclui no habitus da sociedade. Apresentase o estudo de caso da gestão da marca Havaianas que conseguiu transformar em duas décadas o seu valor simbólico de popular a cultuado por todas as classes sociais. Como resultado, a marca gera a identidade, estabilidade, sacia desejos e une os grupos sociais.
\end{abstract}

Palavras-chave: branding de moda, economia simbólica, design.

\section{The Symbolic Construction in the Brand Management of Havaianas}

\begin{abstract}
Contemporaneity is considered as the era of brands, in which it is omnipresent and omnipotent. The objective of this research was to study the social place of the brand in contemporaneity, configured in the social and cultural spheres, in order to identify the occurrence of the process of valorization of its image. The symbolic capital raises the economic capital and creates an identity relationship with its customers. The massive investment in communication in the various ways causes inculcation of the brand in the minds and includes it in the habitus of the society. It presents the case study of the brand management of Havaianas, that managed to transform in two decades its symbolic value from popular to worshiped by all social classes. As a result, the brand generates identity, stability, satisfies desires and unites social groups.
\end{abstract}

Keywords: fashion branding, symbolic economy, design. 


\section{INTRODUÇÃO}

A marca é um símbolo, um meio essencial para que as empresas se manifestem visualmente e sejam fixadas rapidamente na mente das pessoas. As marcas são mais do que simples nomes. Branding ou gestão de marca designa muito além de sua representação gráfica. Significa dizer que, absolutamente, todos os pontos de contato que a empresa pode estabelecer com o público, incluindo outras empresas, é a marca. Como afirma Lipovetsky (2005, p.15), "A imagem de uma marca corresponde, então, ao conjunto de associações estocadas na memória de um consumidor". Branding é uma atividade multidisciplinar de criação e desenvolvimento de projetos de produtos e mensagens visuais, associada às realidades econômicas, sociais, culturais, geográficas que atendam às necessidades de um determinado público.

A configuração da marca moderna surgiu há cerca de cento e cinquenta anos, desenvolvendo-se com o comércio da era industrial, mas ela vem se tornando "onipresente" e "onipotente" nos últimos anos. Segundo Semprini (2006), a marca se modificou profundamente nos últimos vinte anos em relação à sua posição nos mercados e espaços sociais. Neste artigo, pretendemos apontar as relações culturais e sociais destas esferas ainda pouco exploradas pelas pesquisas sobre marcas e ir além, propondo um olhar sobre a sua economia simbólica.

Dentre os métodos de pesquisa, escolhemos o estudo de caso por ser bastante adequado na compreensão dos fenômenos sociais e análise das fontes de evidências, como documentos, artefatos, entrevistas 
e observações (YIN, 2003). A pesquisa exploratória teve abordagem qualitativa e foi realizada a partir da teoria sociológica aplicada ao campo da arte desenvolvida por Pierre Bourdieu, contudo aplicada ao campo do branding neste trabalho. $O$ estudo de caso foi realizado pelo levantamento de materiais disponíveis na internet, jornais e revistas. A comunicação da marca foi analisada a partir do site da Havaianas, de sua publicidade, ações promocionais e da repercussão dessas ações nas mais diversas plataformas midiáticas, de forma a construir o habitus contemporâneo, identificando as noções vigentes à construção simbólica de sua posição.

Para Bourdieu (2005), Habitus configura um conjunto de esquemas inculcados pela educação familiar, desde a infância e pelo convívio em sociedade, que nos mostram os limites conscientes dos grupos e classes sociais e seus campos de sentido. O habitus, adquirido pela formação familiar, é condição à estruturação das relações escolares que, transformado pela ação escolar, torna-se o princípio de todas as experiências posteriores, sejam elas práticas profissionais ou a recepção das mensagens da indústria cultural. O processo de simbolização faz parte de nossa sociedade e cumpre seu papel de legitimar e justificar as estruturas que delimitam o espaço social.

Para nossa análise da influência da marca na estrutura social, selecionamos um caso que fosse representativo e que nos proporcionasse observar sua produção, reprodução e circulação, de forma a demonstrar o papel das marcas na sociedade contemporânea. Escolhemos a Havaianas pela vasta fonte de informações, por ser uma marca brasileira global e, principalmente, por sua trajetória de posição simbólica: de popular à erudita. Buscamos compreender sua influência no habitus da sociedade brasileira contemporânea.

O site oficial da marca Havaianas, cuidadosamente desenvolvido para ser um portal na busca de informações sobre a história da empresa, indica os momentos-chave na gestão de sua marca. É a partir destes marcos indicados pela empresa que foi feita a análise de seu branding. $O$ site foi o ponto de partida na 
análise da marca, apresentando a história e ações mercadológicas de gestão. Examinou-se sua imagem, construída pelos anúncios impressos e vídeos, observando seu consumo e valor simbólico, refletindo-se sobre a estrutura social que determina o seu capital simbólico.

\section{A ECONOMIA SIMBÓLICA E O BRANDING}

Ao gerir a marca, uma empresa precisa extrapolar as fronteiras do campo da administração e desenvolver estratégias e ações no campo da economia simbólica. Para a construção simbólica da marca, a comunicação é a instância principal, pois faz o elo entre corporação, seu público, concorrentes e a sociedade.

Segundo Heilbrunn (2002), uma empresa se posiciona num dado "papel", segundo a percepção almejada por ela pelo mercado. No comércio de refrigerantes, marcas como a Virgin-cola ou a Pepsi-cola se posicionam como anti-heróis que buscam, justamente, desestabilizar o herói da história, a líder Coca-cola. O posicionamento adotado pela marca é divulgado ao mercado por sua comunicação corporativa.

O "papel" adotado por uma marca é inserido numa fórmula narrativa a ser contada, como se houvesse uma história, apresentando um problema a ser resolvido. A resolução deste problema é a missão do protagonista, neste caso, da marca, que se apresenta como espécie de herói da cena. Marcas funcionam como figuras metafóricas da organização que elas representam (HEILBRUN, 2002).

Os produtos que adquirimos, geralmente, são mais pelo que significam simbolicamente do que pelo uso que fazemos deles. É por essa força que a imagem de marca representa o fundamento de uma empresa. Por que as pessoas não compram mais produtos, mas sim marcas, ou melhor, aquilo que lhes foi inculcado de forma sistemática pela propaganda. E o que se compra não é o signo-marca, mas a imagem refletida nos indivíduos. Ela é o símbolo que liga o indivíduo ao grupo, 
a um estilo de vida, a uma cultura, a um status e à autoimagem do consumidor.

Para Tybout e Calkins (2006), uma marca pode elevar ou diminuir um produto - ela funciona como um prisma, e a forma como os indivíduos percebem um produto de marca é filtrado por ela. Para demonstrá-lo, Calkins perguntou a seus alunos de MBA quanto pagariam por um par de brincos de boa qualidade de ouro $18 \mathrm{~K}$, cravejado por dois diamantes de $60 \mathrm{mg}$. Responderam que pagariam U\$550,00. A um segundo grupo de alunos perguntou a mesma coisa, mas acrescentou "brincos da Tiffany", uma joalheria de luxo, e a resposta foi de U\$873,00. A um terceiro grupo, trocou "da Tiffany" por "do Wall-Mart", rede varejista popular, e o valor respondido foi U\$ 81,00. O resultado foi interessante, pois demonstrou a influência do prisma da marca ao mesmo produto. Para este resultado, os alunos precisariam conhecer previamente a posição das empresas citadas, ou seja, seu capital simbólico.

O funcionamento do mercado de bens simbólicos foi teorizado por Pierre Bourdieu, sociólogo francês, que o fez a partir da observação do campo da arte. Por que obras de alguns pintores, por exemplo, valem, não raramente, mais que as de outros? Como se chega a este valor? Não está em jogo o valor da tela, pincéis, tintas e horas trabalhadas no quadro, mas uma intrincada rede social que se relaciona e mede forças, determinando quem ficará em evidência e quanto valerá uma obra. Partindo da teoria da economia das trocas simbólicas do campo da arte de Bourdieu, analisa-se a produção simbólica do campo do branding de moda.

Para Bourdieu (2005), no mercado de bens simbólicos encontramos duas forças que se encontram: os produtores eruditos, classe que dita marcas de distinção que são percebidas e aceitas pela própria classe, além de produzir suas obras para seus pares, que determinam o seu reconhecimento; e a indústria cultural que produz e atende ao grande público. As obras do campo erudito são obras que exigem do receptor uma disposição estética, enfoques específicos e detêm uma estrutura complexa, que também exige o conhecimento histórico da estrutura anterior e, por isso, tornam-se 
acessíveis a um pequeno grupo detentor do código refinado. Os grupos, em níveis mais próximos a este, tentam transgredir este limite e passar a fazer parte do grupo erudito.

Também verificamos esta relação de "luta" entre as marcas; as "eruditas" são as líderes de mercado, que inovam e diferenciam seus produtos. São elas que ditam as regras do mercado. Há as marcas concorrentes que tentam ser fortes como as líderes. E há as populares, que se inspiram naquilo que as líderes produzem e na maneira como se comunicam com o mercado.

É no processo de circulação e de consumo que se constitui o sentido público da obra de arte ou da marca. Segundo Bourdieu (2005), em um campo de produção cultural há um público que consome as obras, os produtores de bens culturais, diferentes instâncias de consagração que competem pela legitimidade (premiações, academias, mídia) e categoria profissional, seja ela de artistas ou marcas. A relação de oposição e complementaridade entre o campo de produção erudita e o campo das instâncias de conservação e consagração forma princípio fundamental da estruturação do campo de produção e circulação dos bens simbólicos. Outro princípio deriva da oposição entre o campo de produção erudita e a indústria cultural, popular.

No processo de circulação do bem simbólico, o crítico é instância importante para legitimá-lo por se tratar de um especialista. No caso da arte, ele tem a função de emitir um parecer sobre a obra e o artista, pois fala como intelectual e influencia seus leitores à medida que the é atribuído tal poder. $O$ público de um crítico está estruturalmente afinado com ele, com sua visão de mundo social, suas preferências e com seu habitus (BOURDIEU, 2005).

No caso da marca, os editores e diretores de veículos de diversas mídias são fundamentais. Conseguir um espaço nos veículos de comunicação, através de mídia espontânea, dá notoriedade e fortalece a imagem da marca.

Um exemplo de "mídia espontânea" para a marca Havaianas foi a capa da revista Marie Claire (2010), que traz uma chamada de destaque à entrevista do mês, com 
o seguinte: "Patrícia Field, figurinista de Sex and the city: 'Bacana é usar joias com Havaianas'." A matéria identifica Patrícia Field como a "costume designer mais badalada do momento", responsável pelos figurinos do seriado americano "Sex and the city" e o fashion movie "O diabo veste Prada". A revista Marie Claire de grande circulação no Brasil qualifica a costume designer como uma "crítica erudita" do campo da moda e o que ela afirma se torna regra. Com esta matéria publicada, a marca Havaianas legitima seu valor e reafirma que seu produto, apesar de popular, pode ser usado pela elite, que se diferenciará pelo uso de outros elementos na vestimenta, como as joias.

Assim como Bourdieu (2005 e 2006), Wolff (1981) descreveu de que forma os editores, críticos, curadores, diretores de revistas influenciam o mercado. Tanto os modos de produção erudita, quanto os da indústria cultural têm suas diferenças expostas pelas instâncias de consagração.

Analisando a escala hierárquica das obras de arte apresentada por Bourdieu é possível sugerir que também hajam níveis no campo das marcas. Ao abordar as marcas de luxo, eruditas, Lipovetsky (2005, p.15) afirma que, atualmente, o setor também é constituído de um mercado hierarquizado, diferenciado, diversificado, no qual "o luxo de exceção coexiste com um luxo intermediário e acessível". Desta forma, considera que há várias modalidades de luxo para diferentes públicos. Então, como os eruditos se diferenciam dos populares?

Os grupos de status social se distinguem entre si de maneira muito sutil, e os de nível mais elevado são os que mais detêm o domínio do refinamento, seja ele por meio da linguagem, vestuário, decoração ou de todo o habitus. O princípio deste sistema expressivo consiste na diferença pela oposição dos elementos.

Numa sociedade como a nossa, em que inúmeros são os grupos sociais, é necessário que a diferença se faça diferente como, por exemplo, o conceito de simplicidade ou de pseudosimplicidade, tal como o princípio de denegação empregado pelos marchands (BOURDIEU, 2006). Nas pessoas simples, há uma 
simplicidade que é muito diferente da simplicidade dos refinados (BOURDIEU, 2008).

A sandália Havaianas se enquadra como exemplo de modo emblemático. Ela é um produto simples que pode ser usado por qualquer pessoa de diferentes classes sociais. Não é à toa que seu slogan é "todo mundo usa". Entretanto, a simplicidade é diferente entre as classes sociais e se distingue pelos outros objetos que a pessoa porta ou pela sua maneira de se comportar e falar.

O que costumamos chamar de "bom gosto" é a competência necessária em apreender e decifrar índices. Os estetas, que se orientam pelos signos exteriores de qualidade, escolhem seus produtos em marcas e locais designados pelo grupo social. As marcas de luxo lançam fórmulas narrativas, demonstrando o estilo de vida do grupo a que se destina, sugerindo produtos que se enquadram nos padrões da classe e em seu modo de uso das classes altas.

O habitus é responsável por incutir noções de consumo a partir da lógica de funcionamento do mercado simbólico. A imagem é usada em vários suportes (em exposições de arte, produtos, mídia impressa, TV, internet) para narrar a ideologia da marca que, de forma consciente ou inconsciente, é percebida pelos consumidores de acordo com o seu repertório. As imagens testemunham a estrutura de pensamento e representações de uma determinada época.

\section{A CONSTRUÇÃO SIMBÓLICA DA MARCA HAVAIANAS}

Escolhemos a marca Havaianas para exemplificar a estrutura de construção da economia simbólica por meio de ações planejadas. Ela é um caso diferenciado por ser uma marca brasileira globalizada que apresentou uma migração de valor entre extremos - de popular a 
$\mathrm{cool}^{3}$. "O que era uma commodity utilizada pelos mais pobres se tornou objeto de desejo de todas as classes sociais no mundo inteiro, graças a um exemplar programa de gerenciamento de marca" (HSM Management, 2005, p.1). O sucesso de sua globalização e migração de valor é raramente testemunhado no mundo empresarial brasileiro.

\subsection{A trajetória da marca Havaianas}

A empresa São Paulo Alpargatas é produtora das sandálias da marca Havaianas, além de outras marcas de calçados conhecidas. A unidade de negócios da marca Havaianas é a responsável pela maior receita da empresa e, sem sombra de dúvidas, é sua marca mais valiosa, hoje considerada ícone do Brasil. Uma marca e um produto que, como seu slogan posiciona, "todo mundo usa". Entretanto, a posição de marca líder do segmento e desejada pelas pessoas só foi alcançada depois de um forte processo de gestão da marca desde 1994.

A sandália começou a ser produzida em 1962 com o posicionamento da marca popular. Sua comunicação se dirigia ao mercado de massa, utilizando somente publicidade nos veículos de mídia eletrônica TV - de consumo da população de baixa renda. A Havaianas foi a primeira marca a fazer merchandising na TV brasileira, patrocinando, na década de 1960, o programa humorístico "A família Trapo" com Ronald Golias e Jô Soares no elenco ${ }^{4}$. A partir de 1970, em função do número de cópias de sandálias existentes no mercado, a campanha publicitária focou as qualidades da sandália original com o garoto-propaganda Chico Anysio ${ }^{5}$, dizendo: "não deformam, não soltam as tiras e

3 O termo cool, da língua inglesa, é um adjetivo utilizado no contexto informal que qualifica alguém ou algo como "descolado" ou "sofisticado e moderno".

4 Ver <http://compublicidade.wordpress.com/2009/06/21/havaianas/>e $<$ http://www.youtube.com/watch? $v=$ PZkACiwgQPs>

${ }_{5}^{5}$ Chico Anysio, comediante da TV brasileira. De 1973 a 1980 teve um programa semanal na Rede Globo, chamado Chico City. Pelo seu 
não têm cheiro". E o slogan "Havaianas, As legítimas" foi então lançado (HAVAIANAS).

Durante a década de 1980 , foram vendidos mais de 80 milhões de pares de sandálias por ano. Segundo Gomes (2010), no período de 1988 a 1993, a Alpargatas começou a verificar uma forte queda no volume de vendas das Havaianas, que foi apontado como resultado de seu posicionamento de mercado: bom, barato e voltado ao consumidor de baixa renda. O prestígio da marca estava em queda.

A década de 1990 se caracterizou pela supervalorização da marca, que passou a ser ostentada na identificação de grupos sociais (LIPOVETSKY, 2005). O jovem e o cool apontavam neste contexto como tendência de linguagem, e a comunicação da Havaianas passava longe desta tendência, enfocando a valorização da qualidade do produto (abordagem racional) e a linguagem popular.

Sandália de borracha é o tipo de calçado de menor valor que há (pelo menos era até aquele momento), de forma que a população de baixa renda a usava em seu cotidiano. A classe média a calçava para os momentos de limpeza da casa e raramente a usava para ir à praia, pois remetia à cultura popular. "Eram uma espécie de atestado de pobreza, a tal ponto que até os pobres passaram a rejeitar o produto", lembra Paulo Lalli, diretor da Havaianas (apud VEJA ON LINE. Os chinelos foram só o começo). O produto, apesar de funcional, estava sendo abandonado pela distinção social. A empresa, diante da queda contínua no consumo de seu produto, começou a investir em marketing e pesquisa, dando início em 1994 ao processo de gestão da marca, de modo a sair da competição por commodities e conferir diferenciação ao produto.

Para Ricardo Palmari (apud GOMES, 2010), gerente de marketing da Alpargatas, a empresa sabia que a classe média gostava das sandálias, mas tinha vergonha de usá-las em público por serem usadas por

sucesso e o de seus personagens, Chico foi escalado como garotopropaganda. Foi uma parceria de sucesso, o sucesso da TV dando força à marca e a campanha da Havaianas gerando maior índice de Ibope ao programa humorístico. 
classes sociais mais baixas. Para atingir o consumidor de classe média foram lançadas as Havaianas Top em 1994, "modelos monocolores que foram desenvolvidos com base na observação do comportamento dos próprios consumidores, que viravam a palmilha para deixar o chinelo de uma cor só" (GOMES, 2010), hábito iniciado pelos jovens de classe média na praia.

Com a nova sandália foi lançada uma nova fórmula narrativa na sua publicidade, substituindo o slogan "Havaianas, As legítimas" para "Havaianas. Todo mundo usa" e contratando várias celebridades como garotos-propaganda da marca. A nova campanha publicitária mostrava o carismático ator Luiz Fernando Guimarães, invadindo as casas de Malu Mader e Bebeto para entrevistá-los e mostrar que a sandália estava nos pés de pessoas famosas em sua intimidade ${ }^{6}$. A fórmula narrativa prosseguiu em mostrar celebridades usando a sandália, não só em sua vida privada, mas, também, em momentos sociais como ir ao restaurante, shopping, festas. A campanha, na TV, com artistas usando-a e dizendo que adoravam e que sempre a usaram, inculca o slogan "todo mundo usa" e torna natural, à classe média, o consumo da Havaianas em casa, na praia ou em outras situações do dia a dia.

Até 1993 havia um único modelo de sandália com três opções de cores. A partir de 1994, foram criados quarenta modelos em dez cores na linha Havaianas Top. Se por um lado houve uma diferenciação - a do produto - por outro, ocorreu uma inovação na comunicação - a que rompeu com a noção de sandália de borracha restrita à praia ou à piscina. Desde então, o olhar sobre o produto se modificou e o comportamento também. A informalidade decorrente do uso de sandálias de borracha passou a ser permitida em mais situações. Um anúncio televisivo, protagonizado pelo galã Rodrigo Santoro, estimulou essa informalidade7. Nele, o ator aparece bem vestido em um restaurante sofisticado, calçando o par de Havaianas. O recepcionista o impede de entrar, porque não é permitido com sandálias.

6 Ver <http://www.youtube.com/watch?v=PI_7SWmWm40 > e

$<$ http://www.youtube.com/watch? $v=y L v V v N a p ~ s g>$

7 Ver <http://www.youtube.com/watch? $v=$ =2StoVkQC70> 
Naquele momento, algumas bonitas jovens se levantaram de suas mesas e, indignadas, diziam que se ele tivesse de se retirar, elas também sairiam. Uma delas disse: "Moço, isso não é sandália. É Havaianas". Outra: "Todo mundo usa". E a outra: "E o direito de ir e vir? E a constituição?". Encontramos, neste vídeo, o cerne da campanha de valorização da marca. A imagem de marca transformou o olhar sobre o produto. A marca valorizada abre as portas para ir a qualquer lugar, mesmo que o produto seja "inadequado" socialmente. O uso das Havaianas em situações formais chegou a gerar duas reportagens do jornal The New York Times, questionando a conveniência de usá-las em ambientes de trabalho, hábito adotado por muitos americanos no verão (VEJA ON LINE. Os chinelos foram só o começo).

Outra estratégia de fomento às vendas foi a de lançar anúncios com o mote de que não bastava ter apenas um par de Havaianas, mas vários, por serem tão lindos e merecedores de serem colecionados. Aos espectadores, a mensagem que aparecia era a de beleza, novas cores, ter vários pares para combinar com todas as roupas. Um discurso pela estética e, também, pelo aumento do consumo. A partir de 1997 (HAVAIANAS), deu-se início ao processo de diferenciação e segmentação de mercado que ampliou o número de linhas de sandálias, acompanhando o fenômeno mundial de atendimento a segmentos cada vez menores de usuários. Atualmente, a Havaianas possui inúmeros modelos e combinações.

O trabalho de branding, cuja ponta do iceberg foram as imagens na mídia e o "novo" produto teve todos os seus desdobramentos no ponto de venda, distribuição, vendas, produção. Essa mudança foi profunda para a Alpargatas que precisou modificar sua estrutura, baseada em funções para uma organização fundamentada em unidades de negócio, tornando-se uma empresa de gestão de marcas, sendo a Havaianas, a principal. Neste período, a fábrica em Campina Grande recebeu novos equipamentos, funcionários foram treinados para se adaptar à nova mentalidade, o centro de armazenagem aumentou sua capacidade, montou-se um laboratório para o desenvolvimento de cores, e a 
distribuição recebeu um cuidado especial. Até então, as sandálias eram vendidas a granel, o que prejudicava a imagem da marca. Em muitos mercadinhos ficavam amontoadas no canto, sendo colocadas em caixas de outros produtos, juntando pó e gerando uma noção de descaso e desorganização. Foram criados displays para expô-las em destaque nas lojas, além de receberem embalagens. A empresa abriu novos canais de venda mais sofisticados e manteve os canais populares. A estratégia era lançar os novos modelos nos canais de formadores de opinião e, quando ficassem bem conhecidos e desejados, iriam também para os atacadistas (HSM Management, 2005).

À medida que os formadores de opinião (eruditos em seus campos) a usassem, disseminavam o desejo pelo novo modelo. As classes mais próximas a eles teriam seu desejo de consumo fomentado e, quando o produto já tivesse cumprido seu ciclo de vida com o público alvo inicial, migraria às classes inferiores na hierarquia social, dando continuidade às vendas. Para se comunicar com o público formador de opinião, a empresa passou, desde 1996, a investir em mídia impressa e noutras alternativas, além da TV.

A Havaianas controlava o tempo de colocação dos modelos nos diferentes pontos de venda e públicos distintos. Segundo a empresa, o intervalo de tempo de colocação de novos modelos entre os canais de vendas sofisticados e populares teria de ser reduzido. Por exemplo, o ciclo da Havaianas Top foi de três anos e o da Havaianas Trekking de apenas um ano (HSM Management, 2005).

Por isso a necessidade constante de produtos diferenciados, com novas cores, estampas e modelos sendo lançados sistematicamente. Quando um novo produto cumpria seu ciclo de vida com os "eruditos", passava ao mercado popular e, após cumprido esse ciclo de vida, era substituído por novos modelos que chegavam ao mercado num fluxo contínuo de "novidades". O que percebemos é que o tempo de substituição dos modelos vem diminuindo, havendo o apoio da comunicação presente durante todo o ano na mídia. 


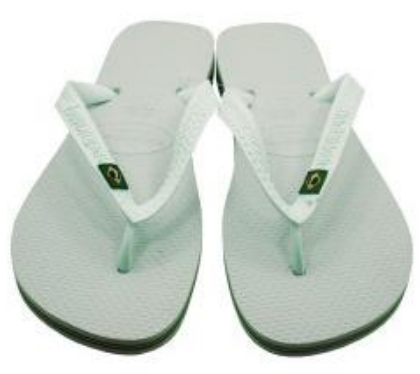

Figura 1: Sandália Havaianas com bandeira do Brasil lançada na Copa do Mundo de 1998.

Fonte:http://www.brasilnabagagem. com.br/chinelos/97-chinelo-

havaianas-branco.html

\subsection{Identidade e consumo da Havaianas na era da globalização}

A exportação das sandálias foi iniciada em 1994 para alguns países da América do Sul. A marca Havaianas passou a ser conhecida com o modelo de sandália, contendo a bandeira do Brasil na tira, lançada para a Copa do Mundo de Futebol de 1998 na França, em pleno verão europeu. O Brasil era um dos favoritos ao título, as atenções estavam voltadas a esse time, e muitas pessoas de outras nacionalidades compravam camisetas do Brasil e passaram a adquirir, também, a sandália (HSM Management, 2005).

Segundo a reportagem da HSM Management (2005), o modelo com a bandeira (figura 1) se tornou "objeto de desejo" no exterior e motivo de orgulho para os brasileiros, o que levou a maior valorização da marca. A estratégia de gestão da marca no exterior se baseava em quatro pilares: pessoas, promoção de eventos, assessoria de imprensa e projetos especiais com lojas. Por pessoas eram entendidos os colaboradores da empresa e os parceiros (distribuidores e revendedores). Os distribuidores de outros países foram selecionados por sua visão de marketing, sua capacidade de assessoria de imprensa e seu relacionamento com formadores de opiniões locais. Os distribuidores é que conseguiram fazer com que a marca tivesse editoriais de moda na revista francesa Elle e, na americana, Cosmopolitan. Em 2003, a ação promocional nas premiações do Oscar e Grammy só foi possível, porque o revendedor nos Estados Unidos tinha acesso aos produtores destes eventos.

Para manter sua expansão, a marca mantém dois trunfos. O primeiro é o de vender as linhas que produz para o mercado brasileiro também no exterior, pois é vista como exótica, originária dos trópicos. Conforme a descrição de um jornalista da revista The Independent Review, de Londres, andar com essas sandálias nos pés na cidade te faz sonhar com a praia, "você desliza num par de Havaianas e, de algum modo indefinível, torna-se um brasileiro honorário" (HSM 
Management, 2005, p.4). O segundo trunfo da Havaianas foi o de se adequar às culturas locais. Na Copa de 2010, a marca colocou no mercado sandálias com as diversas bandeiras dos times participantes da competição, as quais foram postas à venda na internet.

A Havaianas, ao se tornar globalizada e forte, arrisca o crescimento da linha de produtos. Em 2010, decidiu lançar uma linha de tênis que mantêm na sola e na palmilha a mesma borracha da sandália. Estreou na Europa em magazines sofisticados - Harrods e Galeries Lafayette (VEJA ON LINE. Os chinelos foram só o começo). O interessante é que todos os itens da marca são produzidos no Brasil, o que fortalece a imagem da marca, pois "ser brasileira" é um dos pilares de sustentação do discurso de marca no exterior.

A marca lançou uma linha de galochas na loja Selfridge em Londres, com festa para convidados em abril de 2011. No evento, show de Maria Gadú, samba com passistas de escola de samba e muitos elementos da identidade brasileira ${ }^{8}$. A coleção de oito modelos de botas foi batizada de Havaianas Wellies (Figura 2), em homenagem ao primeiro Duque de Wellington, o responsável pela popularização das galochas no século XIX. (HAVAIANAS e o lançamento de galochas).

Figura 2: Galochas batizadas de

Havaianas Wellies, lançadas em 2011.

Fonte:http://www.mariavitrine.com.br/20

11/04/havaianas-lanca-colecao-de-

galochas-na.html.
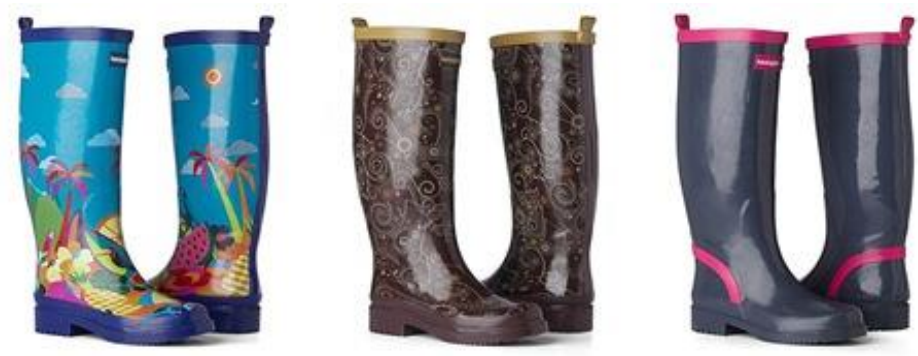

A marca leva a fórmula narrativa do exotismo brasileiro, tão valorizado pelo europeu e se amolda à cultura e demanda inglesa por ser um produto destinado ao clima chuvoso da região. Vários lugares do mundo são chuvosos, inclusive o Brasil. Então, por que dar início ao lançamento em Londres? Porque Londres quer se

8 Ver vídeo do evento em

$<$ http://www.youtube.com/watch? $\mathrm{v}=\mathrm{TsObgSbM8Y \& \text {feature=playere }}$ $\underline{\text { mbedded }>}$ 
posicionar como uma "cidade design" e é considerada pelo "creative people" local de lançamento de tendências.

A estratégia de entrada no mercado externo foi, principalmente, pelas relações públicas e assessoria de imprensa, associando a marca às celebridades. Se, no Brasil, a sandália é um objeto do cotidiano, relacionado ao despojamento e simplicidade, no exterior é um objeto representante do exotismo brasileiro e "so cool".

Em 2009, a AlmapBBDO (HAVAIANAS), agência contratada pela Havaianas, lançou uma série de anúncios denominados "Recortes Brasileiros" para mais de sessenta países. Na figura 3, vemos a imagem de um dos anúncios de mídia impressa (página dupla) com a brasilidade da marca. Seria como se o leitor, ao abrir a página da revista, fosse surpreendido por recortes de imagens que saltariam da revista para ele (simulação de "pop up"). Imagens com explosão de cores e elementos do Brasil, surgindo do universo da Havaianas. Ao calçar Havaianas, as pessoas passam a fazer parte da experiência Brasil: calor, alegria, praia, verão eterno, futebol, turismo, ou seja, os elementos de entretenimento tão desejados por todos.

Figura 3: Anúncio de página dupla de divulgação da Havaianas no exterior, 2009.

Fonte:http://www.flickr.com/photos/juje8 Obis/3452289829/sizes/m/in/photostrea $\mathrm{m} /$.

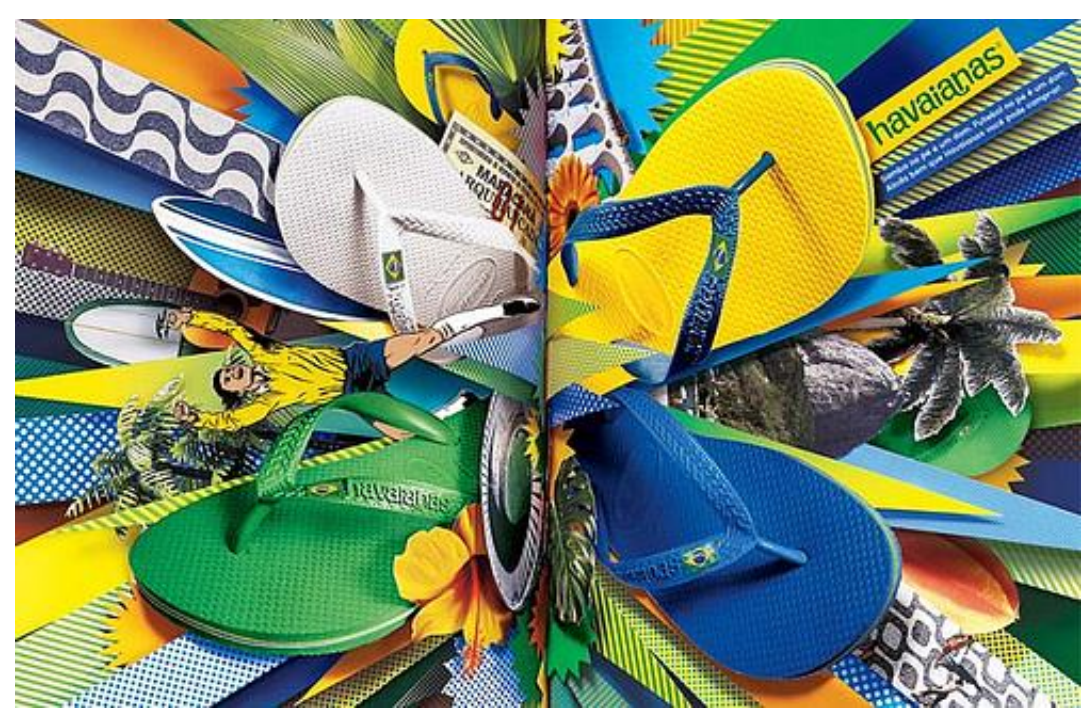

Sendo desejada no exterior, a Havaianas também gera mais valor simbólico dentro do Brasil. Para o povo brasileiro, o que vem de fora do país é muito 
valorizado. A opinião de estrangeiros sobre a marca Havaianas é outro trunfo na comunicação da marca, porque pode divulgar esta opinião, internamente, valorizando-a ainda mais. Alguns anúncios televisivos têm este mote.

A fórmula narrativa da Havaianas produz sentido sobre a nação, tornando-se um elo de ligação da identidade brasileira, já que "todo mundo usa". Ela se coloca como unanimidade, sendo usada por pessoas das mais simples aos ambientes mais sofisticados. A marca por seu conjunto de ações de marketing, publicidade e design consegue promover identificação e distinção a diferentes grupos sociais.

\subsection{A distinção promovida pela Havaianas}

Os trabalhos de assessoria de imprensa, relações públicas e promoção de eventos receberam a mesma prioridade que a área publicitária na divulgação da marca. Essas áreas "garantiam" que todo mundo realmente usasse Havaianas, conferindo credibilidade à mensagem veiculada na campanha. Vários são os exemplos. Em 2002-2003, a assessoria de imprensa da marca inspirou um editorial de moda para a revista Capricho, promovendo a marca às adolescentes. Uma chamada na capa da Marie Claire apresentou uma matéria sobre quão "bacana" é usar Havaianas com joias. São inúmeros os eventos em que a marca distribui sandálias personalizadas aos frequentadores dos camarotes VIPs de eventos como São Paulo Fashion Week ou no carnaval da Sapucaí. A área de relações públicas da marca também envia sandálias de presente a um mailing de celebridades (HSM Management, 2005).

Desde 2003, a marca presenteia cada um dos indicados ao Oscar com sandálias exclusivas. Este tipo de ação promocional vira notícia que, originado da área de relações públicas da empresa, com o trabalho da área de assessoria de imprensa infestou blogs de comunicação, celebridades e área da moda. Gerou curiosidade em saber quais tinham sido os "eleitos" que receberam a sandália exclusiva. Inicialmente, a ação fez parte da campanha da empresa para impulsionar as 
vendas no exterior. Como resultado de celebridades de Hollywood usando a marca, o produto se tornou altamente desejado e chegou a ser encontrado por até 80 dólares no varejo norte-americano (HAVAIANAS E O OSCAR, 2003).

$\mathrm{Na}$ figura 4, o modelo de sandália entregue no Oscar de 2007, com cinco estrelas em ouro branco, diamantes e palmilha diferenciada: ao invés da textura original de arroz, textura de estrelas. O presente estava estimado em US\$1.500,00. A embalagem é um produto à parte. Traça uma grande brincadeira com a claquete, objeto que organiza a produção das cenas durante as filmagens (HAVAIANAS E O OSCAR, 2007).

Ações promocionais são fundamentais à notoriedade da marca. Cada ação promocional exige uma série de outras, articuladas entre as áreas de design, marketing, administração, publicidade e relações públicas, - o branding. O marketing define quais as oportunidades de ações à valorização da marca. A administração apura a viabilidade dos investimentos e do retorno financeiro.

Figura 4: Modelo da sandália Havaianas entregue a estrelas de Hollywood no Oscar 2007.

Fonte:http://www.espacodamoda.com/20 07/03/havaianas-de-brinde-no-oscar-
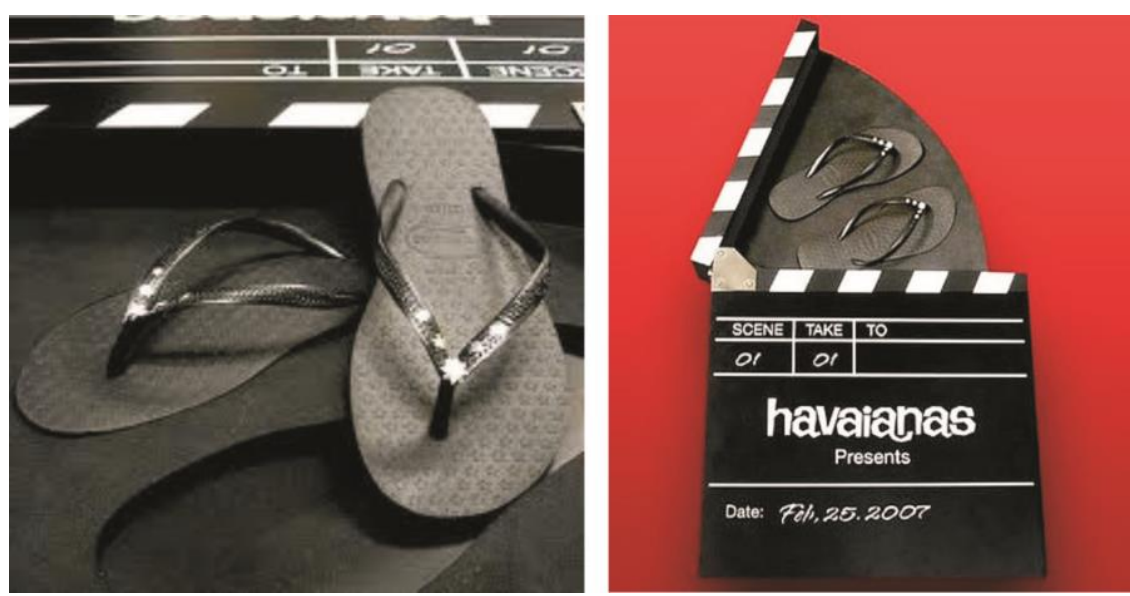

Designers desenvolvem o produto específico e sua embalagem, como na ação do Oscar 2007, em que a sandália foi concebida com uma textura diferente da original, com aplicação de joalheria e embalagem própria, fazendo a comunicação da marca com o evento (Oscar) e com o homenageado. A embalagem e o produto têm a função de comunicar ao presenteado que não é um brinde qualquer, mas muito exclusivo. Tem o 
objetivo de ser tão cool que o presenteado realmente faça uso e, ao usar, crie a aura de distinção do produto. As áreas de publicidade e relações públicas têm de fotografar e produzir material de divulgação para a imprensa, com o foco na mídia espontânea anterior ao evento (que é o que importa neste tipo de ação), planejar a distribuição do brinde aos eleitos, fotografar e divulgar o uso posterior pela celebridade, de forma a "infestar" a mídia com notas sobre a marca, tornando-a desejada. E, assim, o ciclo de circulação simbólica se completa.

Outro tipo de ação promocional para a distinção da marca é a parceria com outras marcas celebradas, a união de marcas eruditas. A força de uma marca auxilia a fortalecer a outra e vice-versa. Em 2004, foi lançada uma edição especial de sandálias, assinada pela joalheria H.Stern, com acabamento em ouro $18 \mathrm{~K}$ e diamantes em três modelos diferentes. Doze peças foram produzidas, com preços variando entre 8 e 50 mil reais e todas foram vendidas no primeiro mês (GULLO, 2003).

Em fevereiro de 2011, a Havaianas (de olho no mercado externo) firmou parceria com a badalada marca italiana Missoni (REVISTA GLOSS, 2011). A Missoni é uma grife que assim como outras do setor está "democratizando" o luxo, ou seja, levando linhas de produtos acessíveis assinados pela marca à classe média mundial. Os consumidores, sonhando em fazer parte do universo da marca, adquirem um objeto por mais simples que seja, para terem suprido o seu desejo de experimentar esse universo.

Figura 5: Modelo de Havaianas lançado pela parceria com Missoni.

Fonte:http://gloss.abril.com.br/moda/con teudo/missoni-havaianas-619869.shtml.
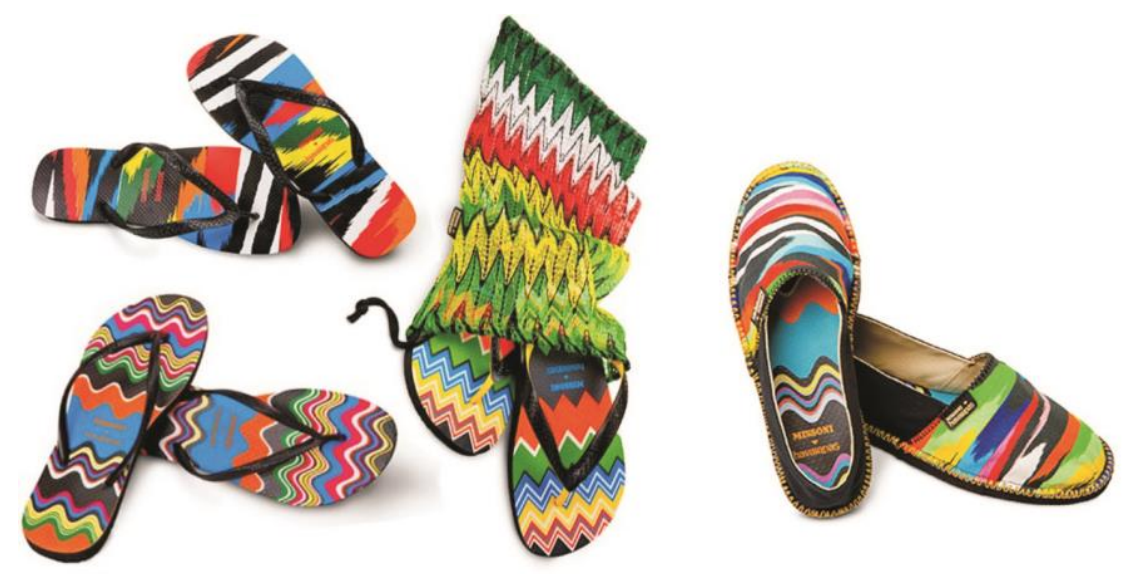
O lançamento da Havaianas-Missoni aconteceu na Europa; foi divulgado pela assessoria de imprensa à mídia que tratou de gerar notícia, imprimindo o desejo em ter tal produto. Criam-se assim as filas de espera pelo produto e o comportamento de "ter antes de qualquer um". Parece superficialidade, mas isso gera distinção social.

Em 2009 foi aberta a loja conceito, denominada "Espaço Havaianas", localizada no endereço mais sofisticado de compras de São Paulo, à Rua Oscar Freire, ao lado das mais prestigiadas marcas do mundo (HAVAIANAS).

O conjunto de imagens produzidas pela Havaianas - vídeos, site, fotos, anúncios impressos, outdoors, vitrines, gôndolas, quiosques, showrooms cria uma imagem única na mente dos consumidores. Ao ver a embalagem do produto, a memória se volta ao último anúncio visto ou àquele mais adorado. Esse lugar ocupado pela marca na mente constrói a realidade da marca e o sujeito se insere neste cenário. Produtos, embalagens, ambiente de venda, tudo se refere à gestão em design.

\section{A GESTÃO DA MARCA E SEU PAPEL NA PRODUÇÃO SIMBÓLICA DA HAVAIANAS}

O branding da Havaianas iniciou em 1994 com o foco na gestão em marketing. Nos dias atuais, a identidade corporativa apresenta uma identidade clara e coerente e cria uma imagem única e global nos seus públicos das mais diversas culturas, porque investe constantemente na visualização de sua fórmula narrativa em diversos tipos de mídia e suportes. Um programa de identidade corporativa e de gestão de marca considerado de sucesso. É uma empresa voltada ao seu design. À medida que a marca foi se tornando valiosa e a empresa entrou na disputa pelo mercado global, percebemos que o design foi se fortalecendo e se tornando estratégico à empresa. Nele, o valor da marca vai além do valor do produto - o usuário não pensa no produto ao calçá-lo, mas sim em todas as outras "imagens mentais" 
construídas pela marca. A inovação e o design se fundem com os objetivos da empresa e formam o fio condutor de sua gestão. A Gestão do Design auxilia a empresa a alterar sua própria imagem, mantendo-a no processo de inovação constante.

Para uma marca ser valorizada, tem de inovar, surpreender e transgredir. Um comportamento análogo ao campo da arte. Na arte, chama a atenção o que se diferencia do discurso existente e, assim também, na marca. Quanto mais gerar notícia, mais valorizada é.

Os produtos de uma marca, assim como a obra de arte, têm uma série de outros custos que não apenas a tela e a tinta ou a borracha. Custos de divulgação, eventos promocionais, o trabalho de uma série de pessoas envolvidas na divulgação do produto e outros, que são somados ao valor de produção do objeto. Por isso, uma Havaianas Missoni custa mais do que o modelo tradicional. Mas, é claro que a empresa investe mais em determinados modelos, o que eleva os custos unitários da sandália, buscando um maior retorno de seu investimento. A marca ainda precisa, constantemente, fazer-se presente na mídia para estar viva na mente das pessoas. É uma importante instância inculcadora do valor simbólico. Caso contrário, abre-se espaço para que outra marca concorrente ocupe este espaço em aberto. As grandes marcas usam a lógica de que quanto mais investirem em publicidade, mais se distanciarão da concorrência, que copiará a sua estratégia. Ou seja, as escolhas que a empresa líder fizer serão as definições do seu segmento.

Havaianas é a marca líder da categoria de sandálias de borracha no mundo. Há outras marcas concorrentes que seguem as definições de mercado da Havaianas. Por exemplo, a comunicação da marca Ipanema trabalha com a alegria, calor, praia, charme, os mesmos elementos que a Havaianas utiliza em suas campanhas. Na mente dos consumidores este é o paradigma de comunicação do setor. Os concorrentes se encontram em uma situação delicada, porque se quiserem buscar uma nova fórmula narrativa, que os posicione diferentemente ou que até quebre o paradigma construído pela Havaianas, terão de investir muito em 
divulgação. O que seria inviável à saúde financeira da empresa. Portanto, aos concorrentes diretos de uma grande marca seguir de perto a líder pode ser economicamente interessante.

Há sandálias réplicas, genéricas das originais Havaianas. E é por este motivo que, de vez em quando, a Havaianas produz vídeos para a TV que contenham a importância de se comprar apenas as originais. $O$ público que compraria a versão genérica é o que assiste à TV, de forma que o encaixe deste tipo de anúncio acontece nos programas mais populares dos canais brasileiros.

A gestão do design da Havaianas tem se mostrado eficiente e este processo também é divulgado. Muitas são as revistas do setor de negócios, como Exame e HSM Management, que a usam como exemplo para demonstrar os benefícios da estratégia em design à lucratividade nos negócios.

Em 2009, a AlmapBBDO criou um anúncio de mídia impressa que unia as "legítimas" a uma obra de arte, conforme na figura 6 (HAVAIANAS).

Figura 6: Anúncio mídia impressa que une a marca ao universo da arte. Fonte: http://br.havaianas.com/ptBR/about-havaianas/campaigns/.

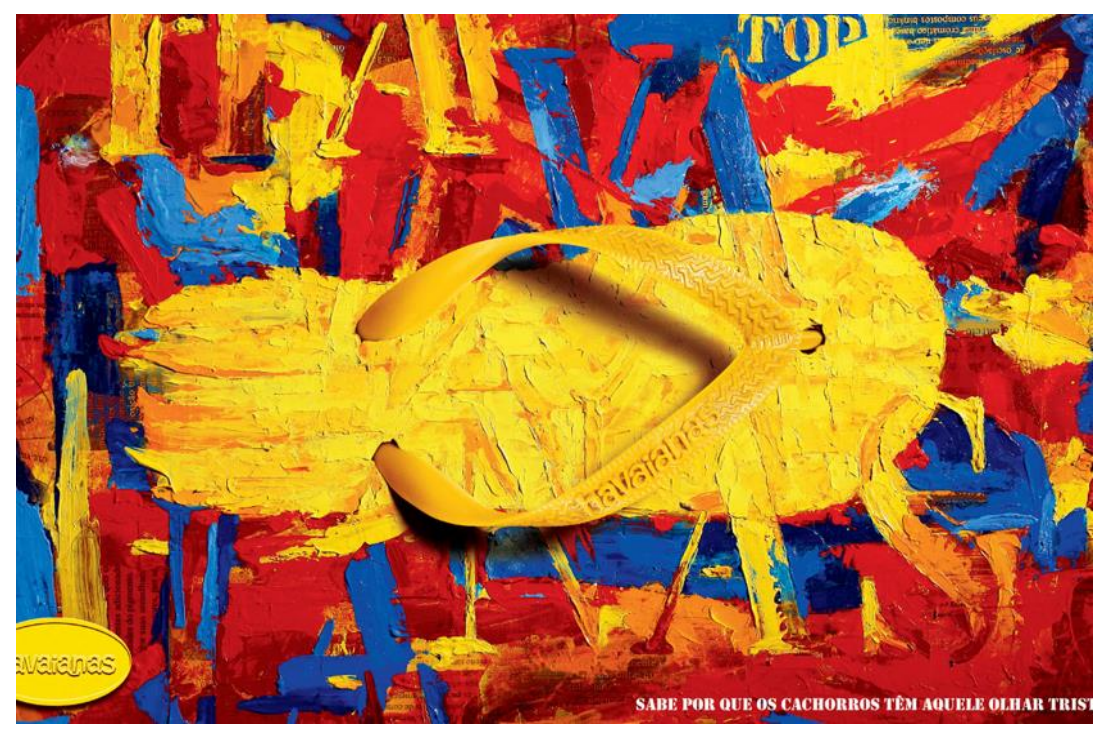

Uma marca valoriza, porque seu capital simbólico cresce e quanto maior for, mais lucra no universo econômico e mais adentra no universo cultural. Ela passa a fazer parte do habitus da sociedade. Não se questiona mais o produto, e a marca se torna representante natural de uma categoria de produtos. As pessoas não falam lâmina de barbear ou amido de milho, é assim com as marcas Gillette e Maizena. E é assim com 
sandálias de uma tira entre os dedos. Todos pedem por Havaianas. Certa vez, testemunhamos numa loja, uma amiga que pedia ao vendedor para "ver a Havaianas da Ipanema". O que ela quis dizer é que gostaria de ver a sandália de uma tira entre os dedos da marca Ipanema. O mais surpreendente é que ninguém estranhou a frase. Significa que a marca Havaianas já adentrou o habitus e a cultura da sociedade atual.

O capital simbólico da marca também pode ser medido na internet, em blogs pessoais e redes sociais. Ao digitar no Google (Janeiro de 2018) a palavra "Havaianas", aparecem aproximadamente 37.000.000 resultados para a pesquisa.

Nas redes sociais identificamos uma série de pessoas que "postam" imagens de suas Havaianas. A marca e suas vidas estão entrelaçadas. Havia em 2011, no Facebook, o Havaianas Europe Oficial, um perfil para os fãs da marca que publicavam suas fotos na praia, na piscina, fotos artísticas das sandálias, doces feitos no formato das sandálias, vestidos feitos com Havaianas. $\mathrm{Na}$ figura 7, fotos de jovens que tatuaram a imagem da marca em seus corpos. À esquerda, um grupo de amigos que ilustrou o produto em seus braços e, à direita, o logotipo tatuado no local exato do pé onde fica o logotipo da sandália.

Figura 7: Fotos de tatuagens postadas no Facebook da Havaianas por fãs da marca. Fonte:http://www.facebook.com/photo.ph p?fbid $=1868621805798 \&$ set $=0.32615895$ 1990\&type $=1 \&$ pid $=1934870 \&$ id $=154868$ 3180 e

http://www.facebook.com/photo.php?fbid $=10150090115597888 \&$ set $=0.32615895$ 1990\&type $=1 \&$ pid $=6061497 \&$ id $=814792$ 887.
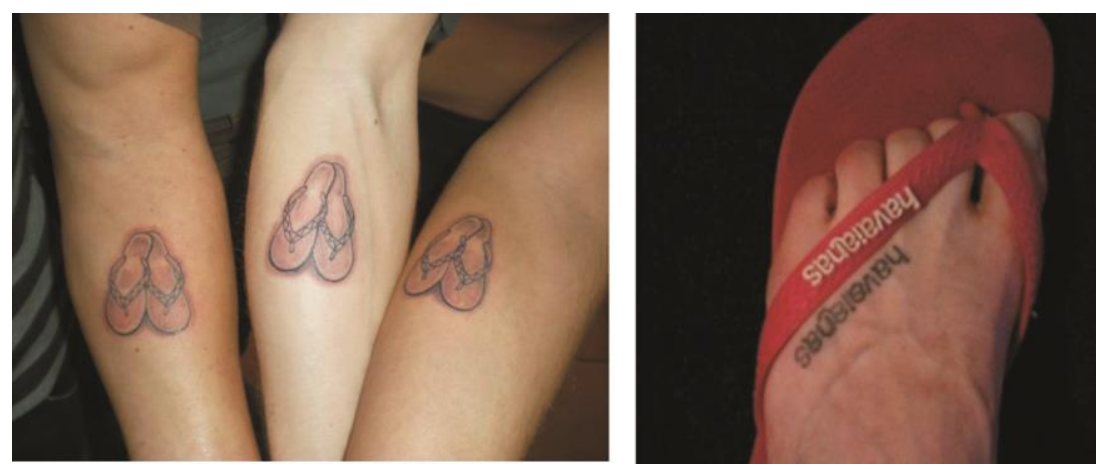

Ao observar essas imagens, percebe-se como a marca é idolatrada e fascina os consumidores. A marca se torna um "ídolo", algo a ser seguido e cultuado. A marca na contemporaneidade pertence à realidade, é ela que posiciona, dá estabilidade, une os grupos sociais, marca o estrato social. 


\section{CONSIDERAÇÕES FINAIS}

Em pouco mais de duas décadas, observamos uma mudança na percepção da imagem da marca Havaianas, como produto destinado às classes baixas e sem valor simbólico, para um produto desejado por todas as classes sociais, com marca valorizada e reconhecida internacionalmente.

As ações de branding que foram realizadas são as responsáveis pelo sucesso na valorização da Havaianas. Neste contexto, o design figura como produtor simbólico importante, pois representa o poder de criação e inovação.

O processo de produção do design pode ser considerado, como descreveu Bourdieu (2005), em um processo coercitivo, aquele que altera o habitus coletivo e o individual, que substitui antigos valores por outros.

A sociedade vê o valor construído pela Havaianas como valor desejado, representante de seu tempo. Entretanto, sabemos que essas são noções construídas e que, de fato, não é apenas a qualidade do produto, a força visual da marca e seus valores os responsáveis pelo valor da Havaianas, apesar do discurso vigente indicar isso; mas, também, a redundância desta mensagem nos diferentes meios de comunicação, até que se acredite, piamente, que é o valor apresentado pela fórmula narrativa o responsável pelo seu encanto. Ressaltamos o poder da mídia como instância inculcadora de valores, tanto quanto a família e a escola. E a importância dos críticos - jornalistas, blogueiros, profissionais de moda - para legitimar o valor da marca por meio de suas opiniões. 


\section{Referências}

BOURDIEU, P. A Economia Das Trocas Simbólicas. São Paulo: Perspectiva, 2005.

A Produção da Crença - contribuição para uma economia dos bens simbólicos. Porto Alegre: Zouk, 2006.

A Distinção - crítica social do julgamento. São Paulo: Edusp; Porto Alegre: Zouk, 2008.

GOMES, F. R. Difusão de Inovações, Estratégia e a Inovação: o Modelo D.E.I. aplicado ao Caso Havaianas. Disponível em: <http://knol.google.com/k/o-caso-sandáliashavaianas\# >. Acesso em: 26 jul. 2010.

GULLO, Carla. Havaianas e HStern.

<https://istoe.com.br/15880_LEGITIMO+LUXO/

hAVAIANAS. Site Oficial - história da marca. Disponível em: <http://br.havaianas.com/pt-BR/about-

havaianas/history/\# >. Acesso em: 20 jun. 2010.

\section{HAVAIANAS E O LANÇAMENTO DE GALOCHAS.}

Disponível em:

<http://www.mariavitrine.com.br/2011/04/havaianas-lancacolecao-de-galochas-na.html>. Acesso em: 30 mai. 2011.

hAVAIANAS E O OSCAR 2003. Comentários de Carlos Merigo. Disponível em:

$<$ http://www.brainstorm9.com.br/diversos/alpargatasdistribuira-havaianas-na-festa-do-oscar/>. Acesso em: 20 mai. 2011.

HAVAIANAS E O OSCAR 2007.

<http://www.bemresolvida.com.br/?tag=havaianas\&paged= 5> Acesso em: 30 mai. 2011.

HEILBRUNN, B. A Logomarca. São Leopoldo: Editora Unisinos, 2002.

HSM Management. Havaianas Com O Mundo A Seus Pés. Edição 48 . Jan- Fev 2005. Disponível em:

<http://www.mctres.com.br/mc3/conteudo/Havaianascomo mundoaoseuspes.pdf $>$. Acesso em: 25 mai. 2011.

LIPOVETSKY, G; ROUX, E. O Luxo Eterno: Da Idade Do Sagrado Ao Tempo Das Marcas. São Paulo: Martins Fontes, 2005.

MARIE CLAIRE. Havaianas e Jóias. Edição 10. Novembro 2010.

REVISTA GLOSS. Havaianas e Missoni na Revista Gloss. Disponível em: 
<http://gloss.abril.com.br/moda/conteudo/missonihavaianas-619869.shtml>. Acesso em: 05 jun. 2011.

SEMPRINI, A. A marca pós-moderna. Poder e fragilidade da marca na sociedade contemporânea. São Paulo: Estação das Letras, 2006.

SETTON, M. da G. J. A teoria do Habitus em Pierre Bourdieu: uma leitura contemporânea. Revista Brasileira de Educação. Maio/Jun/Jul/Ago 2002, no 20, p.60-70.

TYBOUT, A. M.; CALKINS, T. Branding: Fundamentos,

Estratégias, E Alavancagem De Marcas: implementação, modelagem e checklists: experiência de líderes de mercado. Tradução de Ailton Bomfim Brandão. São Paulo: Atlas, 2006.

VEJA ON LINE. Legitimamente Fashion.

<http://veja.abril.com.br/especiais/estilo_moda/p_058.html >. Acesso em: 18 jul. 2010.

VEJA ON LINE. Os Chinelos Foram Só O Começo.

http://veja.abril.com.br/240310/chinelos-foram-comeco-p102.shtml Acesso em: 18 jul. 2010.

WOLFF, J. A Produção Social Da Arte. Rio de Janeiro: Zahar, 1981.

YIN, R. K. Estudo de caso. Planejamento e métodos. Porto Alegre: Bookman, 2003. 